\title{
ANALISA PROYEK PENGEMBANGAN SISTEM INFORMASI PERPUSTAKAAN UMUM MENGGUNAKAN UNIFIED MODELING LANGUAGE
}

\author{
Adi Nurseptaji ${ }^{1)}$, Agusdael Adamsyah ${ }^{2)}$, Mochamad Wildan ${ }^{3)}$, \\ Muhamad Akmal ${ }^{4)}$, Pyan Ardiansyah ${ }^{5}$, , Ricky Firmansyah ${ }^{6}$ ' \\ ${ }^{1-6}$ Fakultas Teknologi Informasi, Universitas Adhirajasa Reswara Sanjaya \\ email: adinurseptaji@gmail.com ${ }^{1)}$, adumuhuy@gmail.com ${ }^{2)}$, mochammadwildanf@gmail.com ${ }^{3)}$ \\ makmalagung@gmail.com ${ }^{4)}$, apyan6@gmail.com ${ }^{5)}$, Ricky@ars.ac.id ${ }^{6}$
}

\begin{abstract}
The library is an important facility as a source of information, especially in the world of education to support learning activities for students and knowledge seekers to add insight and knowledge. To facilitate and accelerate library services, a Library Information System is needed in order to increase productivity, effectiveness and efficiency in the library. For the development stage of the library information system using the Unified Modeling Language (UML) as a tool for modeling and documenting the Library Information System. With the Public Library Information System Development Project Analysis Using the Unified Modeling Language, it is hoped that it can improve service, productivity, effectiveness and efficiency in libraries to increase reading interest for students and facilitate and speed up the transaction process of borrowing and returning books to the library.
\end{abstract}

Keywords: analysis, systems development, library, information systems, unified modeling language.

\section{PENDAHULUAN}

Kemajuan teknologi informasi dan komunikasi pada saat ini berkembang begitu pesat manusia sangat bergantung pada teknologi informasi untuk memudahkan berbagai persoalan atau permasalahan yang ada dengan menggunakan teknologi. Sudah seharusnya pada saat ini dan kedepannya teknologi informasi memberikan dampak yang signifikan terhadap berbagai kendala dan permasalahan yang ada. Begipun dengan kendala yang ada pada pengelolaan data pada perpustakaan dengan menggunakan teknologi sistem informasi perpustakaan agar memudahkan dalam proses pengelolaan data dan informasi yang ada pada perpustakaan. Pengolahan perpustakaan menggunakan sistem manual membutuhkan waktu yang relatif lama dan dapat mengakibatkan koleksi terlambat untuk dilayankan kepada pemustaka yang membutuhkan. Selain itu pelayanan juga akan lebih lama dibandingkan jika sudah tersistem dalam komputer. Hal ini yang menjadikan pentingnya menerapkan sistem informasi untuk perpustakaan (Rahmawati \& Bachtiar, 2018). Sistem adalah seperangkat komponen yang saling berhubungan dan saling berkerjasama untuk mencapai beberapa tujuan (Muhidin, 2017). Sistem informasi adalah gabungan dari software, hardware, infrastruktur dan sumber daya manusia (SDM) yang saling berkaitan untuk menciptakan sebuah sistem yang dapat mengolah data menjadi informasi yang bermanfaat (Erawati, 2019). Sistem informasi perpustakaan adalah proses komputerisasi untuk mengolah data dalam suatu perpustakaan. Semua di proses menggunakan software tertentu seperti software pengolah database. Petugas perpustakaan dapat selalu memonitor tentang ketersediaan buku, daftar buku baru, peminjaman buku, dan pengembalian buku (Firman Astria, 2016). Use Case Diagram Adalah teknik untuk merekam persyaratan fungsional sebuah sistem. Use case mendeskripsikan interaksi tipikal antara para pengguna sistem dengan sistem itu sendiri, dengan memberi sebuah narasi tentang bagaimana sistem tersebut digunakan (Ruhul Amin, 2017). MySQL sebenarnya merupakan turunan salah satu konsep utama database sejak lama, yaitu SQL (Structured Query Language). SQL adalah sebuah konsep pengoperasian database terutama untuk pemilihan atau 
seleksi dan pemasukan data yang memungkinkan pengoperasian data dikerjakan dengan mudah secara otomatis (Warman \& Ramdaniansyah, 2018). Bahasa Pemrograman Bahasa buatan yang digunakan untuk mengendalikan perilaku dari sebuah mesin, biasanya berupa mesin komputer, sehingga dapat digunakan untuk memberitahu komputer tentang apa yang harus dilakukan (Hardiyanto et al., 2019). Hypertext Prepocessor (PHP) adalah bahasa program yang berjalanpada sebuah web server, atau sering disebut server- side (Harison \& Syarif, 2016).

\section{METODE PENELITIAN}

Dalam pengembangan software penulis menggunakan metode waterfall. Model waterfall merupakan model yang bersifat sistematis berurutan dalam membangun sebuah software sistem informasi.

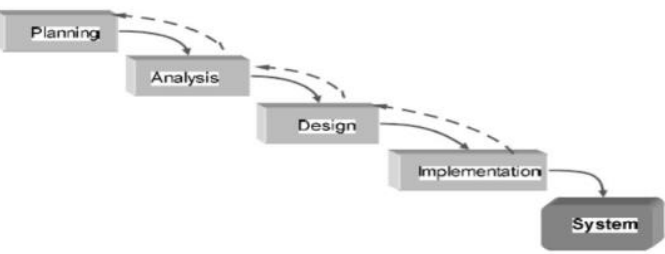

\section{Gambar 1. Linear Sequential Model.}

Linear sequential model ("classic life cycle" atau "waterfall model") adalah metode pengembangan perangkat lunak dengan pendekatan sekuensial dengan cakupan aktivitas:

a) Rekayasa Sistem dan Analisis (System Engineering and Analysis). Karena perangkat lunak adalah bagian dari sistem yang lebih besar, pekerjaan dimulai dari pembentukan kebutuhan-kebutuhan untuk seluruh elemen sistem dan kemudian memilah mana yang untuk pengembangan perangkat lunak. Hal ini penting, ketika perangkat lunak harus berkomunikasi dengan hardware, orang, dan basis data.

b) Analisis Kebutuhan Perangkat Lunak (Software Requirements Analysis). Pengumpulan kebutuhan dengan fokus pada perangkat lunak, yang meliputi: domain informasi, fungsi yang dibutuhkan, unjuk kerja/performansi dan antarmuka. Hasilnya harus didokumentasi dan di-review ke pelanggan.

c) Perancangan (Design). Ada empat atribut untuk program, yaitu: Struktur Data, Arsitektur perangkat lunak, Prosedur detil, dan Karakteristik Antarmuka. Proses desain mengubah kebutuhan-kebutuhan menjadi bentuk karakteristik yang dimengerti perangkat lunak sebelum dimulai penulisan program. Desain ini harus terdokumentasi dengan baik dan menjadi bagian konfigurasi perangkat lunak.

d) Pembuatan Kode (Coding). Penterjemahanperancangan ke bentuk yang dapat dimengerti oleh mesin, dengan menggunakan bahasa pemrograman.

e) Pengujian (Testing). Setelah kode program selesai testing dapat dilakukan. Testing memfokuskan pada logika internal dari perangkat lunak, fungsi eksternal dan mencari segala kemungkinan kesalahan dan memriksa apakah sesuai dengan hasil yang diinginkan.

f) Pemeliharaan

(Maintenance). Merupakan bagian paling akhir dari siklus pengembangan dan dilakukan setelah perangkat lunak dipergunakan, meliputi kegiatan-kegiatan:

Corrective Maintenance: Mengoreksi kesalahan pada perangkat lunak, yang baru terdeteksi pada saat perangkat lunak dipergunakan.

Adaptive Maintenance: Penyesuaian dengan lingkungan baru, misalnya sistem operasi atau sebagai tuntutan atas perkembangan sistem komputer, misalnya penambahan printer driver.

Perfektive Maintenance: Bila perangkat lunak sukses dipergunakan oleh pemakai. Pemeliharaan ditujukan untuk menambah kemampuannya seperti memberikan fungsifungsi tambahan, peningkatan kinerja dan sebagainya (Darmawan, Taghfirul, 2017).

\section{Metode Pengumpulan Data}

Pengumpulan data adalah proses mengumpulkan dan mengukur informasi tentang variabel-variabel penelitian yang ditargetkan dalam suatu sistem yang mapan, yang kemudian memungkinkan seseorang untuk menjawab pertanyaan yang relevan dan 
mengevaluasi hasil (Hayati, 2019). Adapun pendekatan pengumpulan data yang penulis gunakan metode kualitatif diantaranya:

\section{Observasi (Observation)}

Dalam Metode ini penulis melakukan observasi mengamati langsung terhadap berbagai proses kegiatan yang sedang berlangsung didalam perpustakaan pada umumnya guna memperoleh data untuk dibuatkan sebuah pemecahan masalah.

\section{Wawancara (Interview)}

Melakukan wawancara langsung kepada narasumber pengelola perpustakaan mengenai berbagai kendala yang dihadapi terhadap proses kegiatan yang ada pada perpustakaan agar mendapatkan data dan mengetahui lebih jelas permasalahan yang diahadapi saat melakukan observasi atau pengamatan.

3. Studi Pustaka (Literature Study)

Mempelajari dan memahami dari berbagai sumber-sumber yang sudah ada melalui $e$ book, artikel jurnal ilmiah, internet yang berkaitan dengan Analisa Pengembangan Sistem Informasi (Hayati, 2019).

\section{HASIL DAN PEMBAHASAN}

Dalam pengembangan model sistem informasi menggunakan Unified Modeling Language (UML) sebagai tools memodelkan dan mendokumentasikan Sistem Informasi Perpustkaan. UML (Unified Modeling Language) merupakan bahasa visual untuk pemodelan dan komunikasi mengenai sebuah sistem dengan menggunakan diagram dan teks- teks pendukung (Romadhon, 2019). UML yang digunakan dalam pengembangan sistem informasi perpustakaan ini menggunakan Use Case Diagram untuk menggambakan fungsional dari sebuah sistem informasi perpustakaan yang diusulkan. Use Case diagram menggambarkan kegiatan atau juga interaksi yang saling berkesinambungan (continue) antara aktor dan juga sistem (Yani et al., 2019). Perancangan sistem yang diusulkan pada perpustakaan umumnya akan digambarkan menggunakan use case diagram sebagai rancangan fungsional dari sistem informasi yang akan dibuat. Untuk memudahkan pengguna sistem dalam memahami apa saja yang bisa digunakan dalam sistem usulan ini. Berikut dibawah ini gambaran jelas use case diagram yang diusulkan.

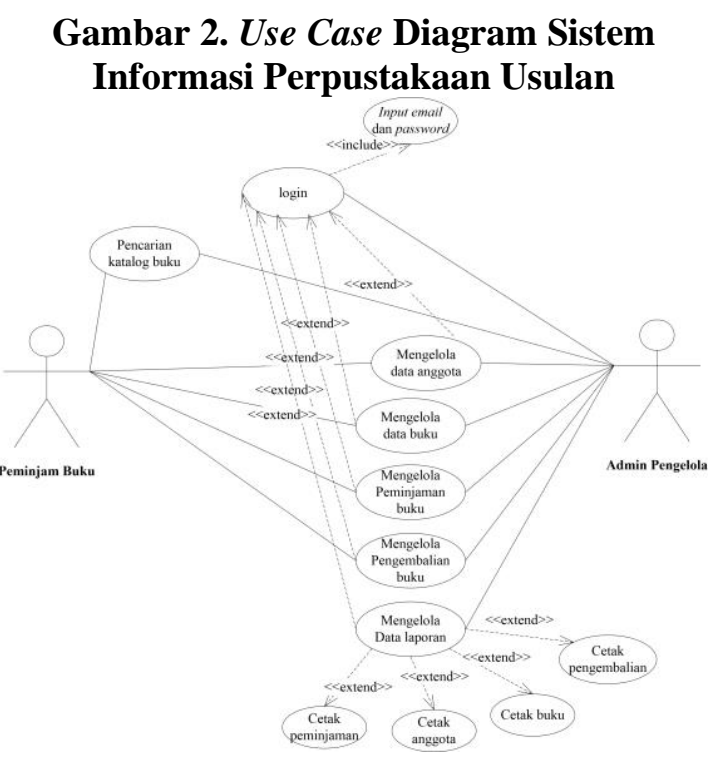

Analisa kebutuhan fungsional sistem informasi perpustakaan yang diusulkan. Perancangan sistem informasi perpustakaan yang diusulkan ini dapat memudahkan kinerja dan meningkatkan produktivitas admin pengelola maupun peminjam buku. Karna dalam proses pengelolaan data perpustakaan akan lebih cepat dan real time. Berdasarkan pada gambar dua diatas dapat dijelaskan bahwa yang dapat dilakukan oleh aktor peminjam buku yaitu melakukakan pencarian katalog buku mendaftar sebagai anggota perpustakaan dan melakukan transaksi peminjaman buku ataupun trasnsaksi pengembalian buku membayar denda jika terjadi keterlambatan pengemablian buku. Sedangkan untuk aktor admin pengelola dapat melakukan pencarian katalog buku login sistem mengelola data anggota mengelola buku mengelola transaksi peminjaman buku maupun transaksi pengembalin buku menerima denda keterlambatan jika peminjam terlambat mengembalikan buku melakukan cetak laporan.

Penjelasan use case diagram sistem informasi perpustakaan yang diusulkan. Use case diagram sistem informasi perpustakaan yang diusulkan terdapat dua aktor yang pertama aktor peminjam buku yang kedua aktor admin pengelola. Yang pertama bisa dilakukan pada sistem informasi perpustakaan 
ini peminjam buku melakukan pendaftaran kepada admin pengelola sistem informasi perpustkaan agar peminjam dapat meminjam buku. Kemudian admin pengelola melakukan login sistem informasi perpustakaan untuk melakukan pengelolaan data anggota. Setelah peminjam buku terdaftar sebagai anggota peminjam buku dapat mengakses halaman katalog pencarian buku untuk mencari informasi buku yang akan dipinjam. Bila peminjam telah mendapatkan buku sesuai dengan yang diinginkan maka peminjam buku datang menuju admin pengelola untuk dilakukan pengelolaan data peminjaman buku pada sistem informasi perpustakaan setelah data berhasil diinput oleh admin pengelola buku dapat dibawa pulang oleh peminjan dengan ketentuan tiga hari peminjaman jika lebih dari tiga hari maka dikenakan denda. Jika peminjam ingin mengembalikan buku datang kembali kepada admin pengelola sistem informasi perpustakaan kemudian admin akan login sistem dan melakukan pengelolaan transaksi pengembalian buku jika peminjam terlambat mengembalikan buku maka sistem secara otomatis akan mengeluarkan peringatan denda yang harus dibayarkan oleh peminjam buku.

Jadwal Kegiatan Proyek Sistem Informasi Perpustkaan.

Adapun jadwal proses pembuatan sistem informasi perpustakaan ini sebagai berikut.

\section{Tabel 1. Jadwal Kegiatan Proyek Sistem Informasi Perpustakaan}

\begin{tabular}{llllll}
\hline No & $\begin{array}{l}\text { Kegiatan } \\
\text { Proyek }\end{array}$ & April & Mei & Juni & Juli \\
\hline 1 & Analisa & & & & \\
2 & Desain & & & & \\
3 & Coding & & & & \\
4 & Implementasi & & & & \\
\hline
\end{tabular}

Spesifikasi Hardware

Spesifikasi Hardware yang direkomendasikan dalam menjalankan sistem informasi perpustakaan ini sebagai berikut:

Tabel 2. Tabel Spesifikasi Hardware

\begin{tabular}{lll}
\hline No & Nama Perangkat & Spesifikasi \\
\hline 1. & CPU (Central & Processor Intel $\AA$ \\
& Processing Unit $)$ & Pentium $®$ Dual Core
\end{tabular}

\begin{tabular}{lll}
\hline & & RAM DDR2 2 GB \\
& & Hard Disk 250 GB \\
& Mouse Usb \\
2. & Mouse Wireless & \\
& & QWERTY \\
3. & Keyboard & Resolusi layar minimum \\
4. & LCD (Liquid & 14 \\
& Crystal Display) & InkJet \\
5. & Printer & All in One \\
\hline
\end{tabular}

\section{Spesifikasi Software}

Untuk menjalankan sistem informasi perpustkaan ini ada beberapa software yang direkomendasikan diantaranya windows 7 ataupun windows 8 untuk mendukung jalannya sistem informasi perpustkaan aplikasi web server seperti XAMPP untuk mendesian database sistem informasi perpustakaan mozilla fireox sebagai web browser untuk menjalankan sistem informasi perpustakaan dan Apche sebagai server untuk menjalankan web browser bahasa pemrograman menggunakan Hypertext Prepocessor (PHP) Macromedia Dreamweaver 8 sebagai text editor dalam menjalankan bahasa pemrograman.

Analisa Kebutahan Brainware

Dalam menjalan sistem informasi perpustakaan untuk mendukung semua proses ini dibutuhkan sumber daya manusia yang kompeten sangat diperlukan untuk menjalankan sistem ini. Diantaranya admin pengelola perpustakaan dimana admin pengelola perpustakaan ini bertanggungjawab penuh terhadap berbagai data perpustakaan yang ada dalam sistem informasi perpustakaan seperti mengelola data anggota data buku melakukan proses transaksi peminjaman dan pengembalian buku mengelola berbagai laporan yang tersedia dalam sistem dengan sangat baik serta melakukan maintenance sistem jika diperlukan. Kemudian peminjam buku dimana untuk peminjam yang bisa dilakukan terhadap sistem adalah melakukan proses pencarian buku melakukan pendaftaran anggota melakukan peminjaman buku serta melakukan pengembalian denda apabila perlu.

\section{Implementasi}

Pada tahapan ini sistem informasi perpustakaan menggunakan implementasi user interface (UI) atau tampilan antarmuka pengguna menjadi daya tarik utama dalam 
sebuah aplikasi. Sebuah aplikasi dikatakan mudah untuk digunakan ketika pengguna dapat mengerti maksud dari tampilan antarmuka dan bagaimana mengoperasikan aplikasi tersebut dengan cepat dan tanpa perlu usaha yang banyak (Ghiffary et al., 2018). Untuk tahap desain user interface menggunakan Balsamiq Mockups adalah aplikasi yang sangat berguna untuk mendesain halaman web. Mockups biasanya di gunakan oleh para designer untuk memulai suatu coretan-coretan, dengan kata lain kalian tidak perlu lagi menggunakan pensil untuk merancang sesuatu (Setiawati et al., 2018).

\section{user interface (UI) Sistem Informasi} Perpustakaan

Halaman katalog pencarian buku pada halaman ini peminjam buku maupun admin pengelola bisa melakukan pencarian buku yang telah tersedia pada perpustakaan.

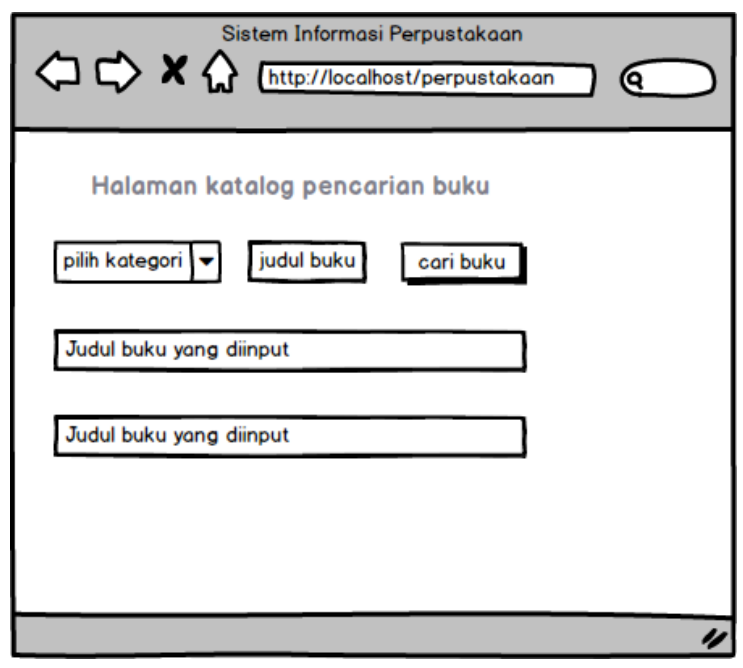

\section{Gambar 3. User interface halaman pencarian kalalog buku}

Halaman login admin pengelola pada halaman ini admin pengelola dapat melakukan login admin dengan menginputkan email dan password.

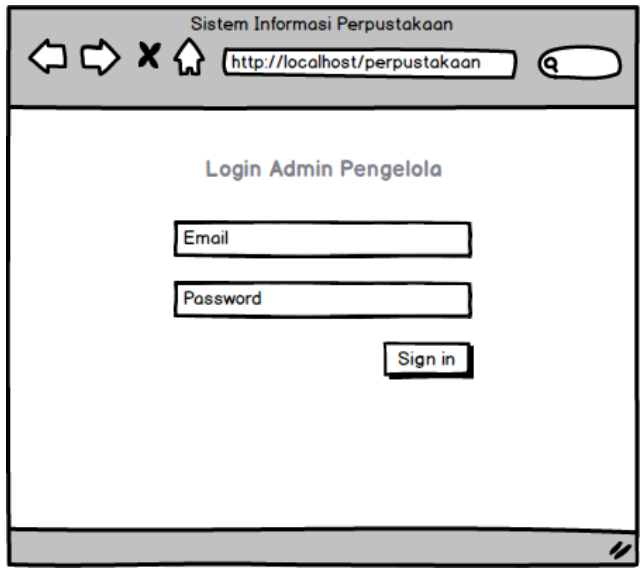

Gambar 4. Admin login user interface

Halaman dashboard admin pengelola halaman ini admin pengelola dapat mengelola berbagai data seperti data anggota data buku, melakukan transaksi peminjaman buku, melakukan transaksi pengembalian buku, mencetak laporan anggota laporan buku laporan peminjaman dan laporan pengembalin buku. Admin pengelola dapat melihat tanggal dan statistik peminjaman buku serta melakukan log out admin.

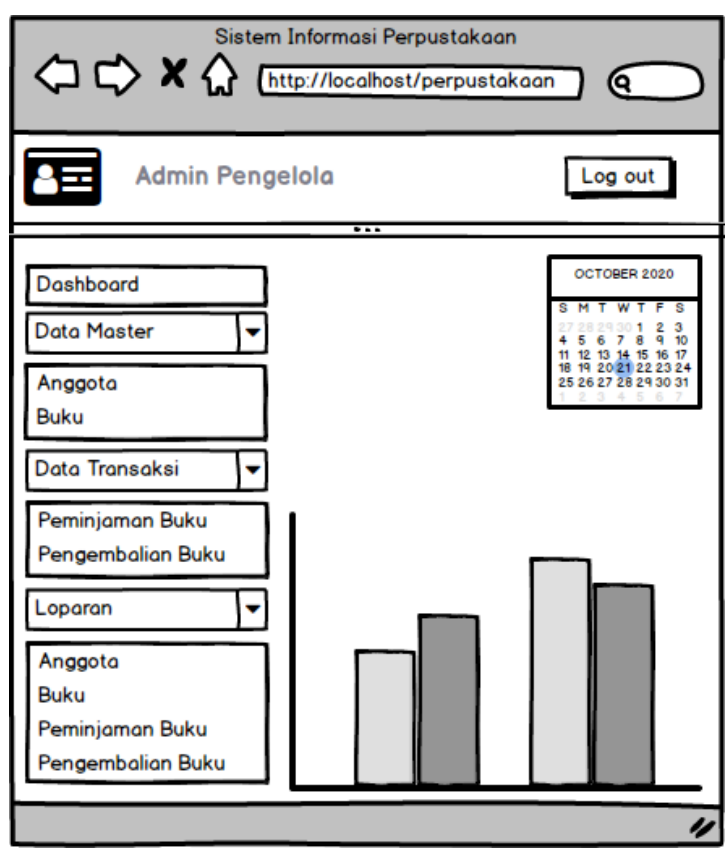

Gambar 5. User interface dashboard admin pengelola

Apabila admin pengelola ingin melakukan tambah anggota maka admin memilih menu anggota lalu akan muncul form tambah anggota kemudian admin melakukan input 
data anggota sesuai dengan form yang telah tersedia kemudian pilih submit.

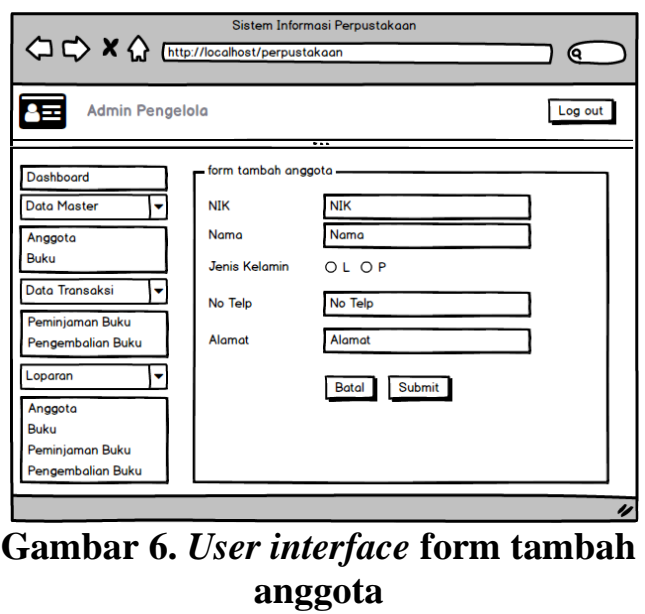

Halaman tambah data buku admin memilih menu buku kemudian akan muncul form tambah buku admin melakukan input data sesuai dengan form yang telah tersedia kemudian pilih submit.

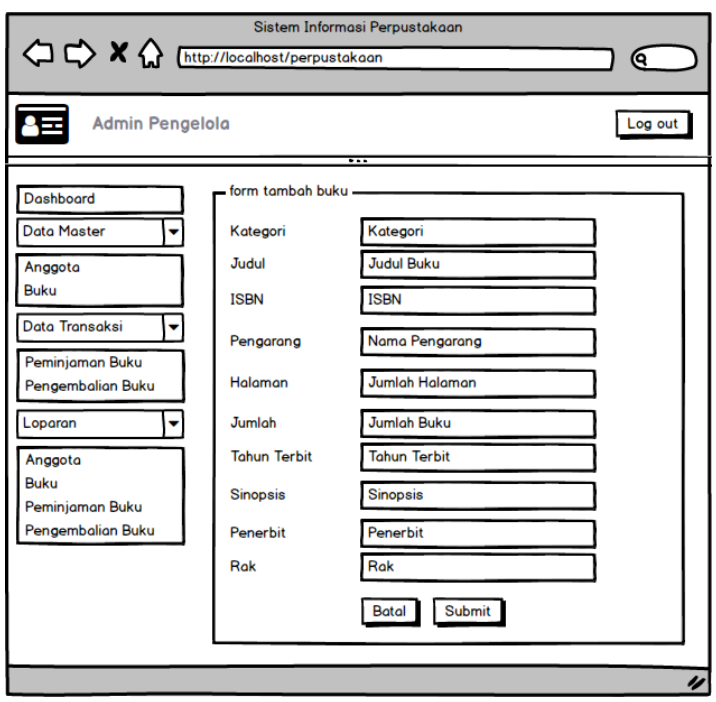

\section{Gambar 7. User interface form tambah buku}

Halaman transaksi peminjaman buku admin pengelola dapat melakukan transaksi peminjaman buku dengan memilih menu peminjaman buku kemudian admin menginput di form yang telah tersedia buku yang dipinjam maksimum tiga buku. Kemudian admin pengelola bertanya kepada pinjam buku tujuan peminjaman buku untuk apa dan admin menuliskan keterangan kemudian tekan menu submit.

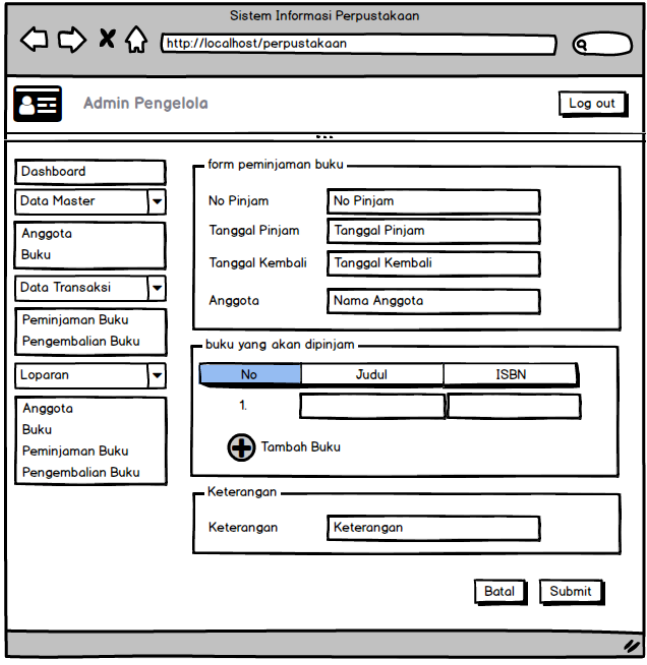

\section{Gambar 8. User interface form peminjaman buku}

Halaman pengembalian buku admin memilih menu pengembalian buku maka akan muncul form pengembalian buku admin cukup menginputkan nama anggota maka sistem akan secara otomatis memunculkan tanggal pinjam tanggal kembali terlambat denda serta list buku.

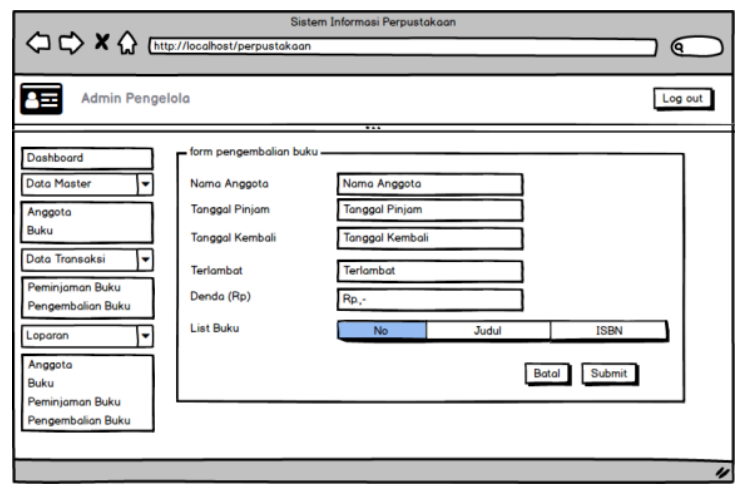

\section{Gambar 9. User interface form pengembalian buku}

Halaman laporan dimana admin pengelola dapat melihat laporan yang tersedia salah satunya laporan memilih menu anggota perpustakan admin pengelola menginput dari tanggal sampai tanggal kemudian klik tampilkan maka sistem akan secara otomatis menampilkan laporan sesuai dengan tanggal. 


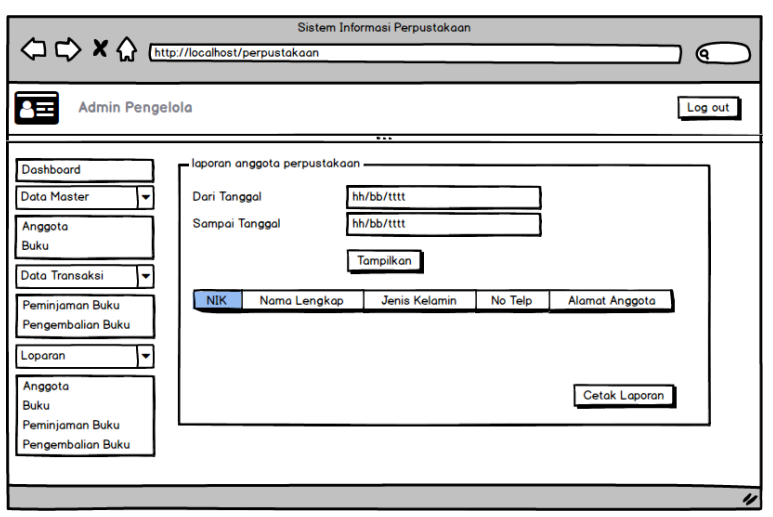

Gambar 10. User interface form laporan anggota

\section{KESIMPULAN}

1. Analisa Pengembangan Sistem Informasi Perpustakaan ini menggunakan metode pengembangan software waterfall.

2. Unified Modeling Language (UML) sebagai tools memodelkan dan mendokumentasikan Sistem Informasi Perpustkaan.

3. Untuk tahap desain user interface menggunakan Balsamiq Mockups adalah aplikasi yang sangat berguna untuk mendesain halaman web.

4. Sistem Informasi Perpustakaan dapat memberikan manfaat seperti mempermudah proses pengelolaan yang ada pada perpustakaan.

\section{REFERENSI}

Rahmawati, N. A., \& Bachtiar, A. C. (2018). Analisis dan perancangan sistem informasi perpustakaan sekolah berdasarkan kebutuhan sistem. Berkala Ilmu Perpustakaan Dan Informasi, 14(1), 76. https://doi.org/10.22146/bip.28943

Muhidin, A. (2017). Perancangan Sistem Informasi Produk Hasil Repair Pada PT. JVC Kenwood Elektronik Indonesia. Jurnal SIGMA, 6(2), 148157.https://doi.org/10.1037/00223514.51.6.1173

Erawati, W. (2019). Perancangan Sistem Informasi Penjualan Dengan Pendekatan Metode Waterfall. Jurnal Media
Informatika Budidarma, 3(1), 1. https://doi.org/10.30865/mib.v3i1.987

Firman Astria, W. H. F. \& N. X. (2016). Sistem Informasi Perpustakaan Online Berbasis Web. E-Journal Teknik Elektro Dan Komputer, 5(2), 29-36.

Ruhul Amin, M. K. (2017). Siswa Baru Pada Smk Budhi Warman 1 Jakarta. 2(2), 113-121.

Warman, I., \& Ramdaniansyah, R. (2018). Analisis Perbandingan Kinerja Query Database Management System (Dbms) Antara MySQL 5.7.16 dan MARIADB 10.1. Jurnal Teknoif, 6(1), 32-41. https://doi.org/10.21063/jtif.2018.v6.1.3 $2-41$

Hardiyanto, Abdussomad, Haryadi, E., Sopandi, R., \& Asep. (2019). Penerapan Model Waterfall Dan Uml Dalam Rancang Bangun Program Pembelian Barangberorientasi Objek Pada Pt. Fujita Indonesia. Interkom, 13(4), 6.

Harison, \& Syarif, A. (2016). Sistem Informasi Geografis Sarana Pada Kabupaten Pasaman Barat. Jurnal TEKNOIF, 4(2), 40-50.

Darmawan, Taghfirul, H. A. (2017). Analisis Pemilihan Penerapan Proyek Metodologi Pengembangan Rekayasa Perangkat Lunak. Teknika, 5(1), 24-31. https://doi.org/10.34148/teknika.v5i1.48

Hayati, R. (2019). Pengertian Metode Pengumpulan Data, Jenis, dan Cara Menulisnya. PenelitianIlmiah.Com. https://penelitianilmiah.com/metodepengumpulan-data/

Romadhon, D. \& S. S. (2019). Perancangan Website Sistem Informasi Simpan Pinjam Menggunakan Framework Codeiginter Pada Koperasi Bumi Sejahtera Jakarta. Journal of Information System, Informatics and Computing, 3(1), 21-28.

Yani, A., Syauki, A., \& Marlina, S. (2019). Rancang Bangun Sistem Informasi Akademik Berbasis Web pada Madrasah Aliyah Attaqwa Tangerang. Jurnal Informatika, 6(2), 255-261. https://doi.org/10.31311/ji.v6i2.6038

Ghiffary, M. N. El, Susanto, T. D., \& Prabowo, A. H. (2018). Analisis Komponen Desain Layout, Warna, dan Kontrol pada Antarmuka Pengguna Aplikasi Mobile Berdasarkan 
(JUSS) Jurnal Sains dan Sistem Informasi

Vol.3 No.2, Desember 2020

Kemudahan Penggunaan (Studi Kasus: Aplikasi Olride). Jurnal Teknik ITS, $7(1)$.

https://doi.org/10.12962/j23373539.v7i1 .28723

Setiawati, A., Rahim, A., \& Kisbianty, D. (2018). Pengembangan dan Pengujian Aspek Usability pada Sistem Informasi Perpustakaan ( Studi Kasus: STIKOM Dinamika Bangsa Jambi ). Processor, 13(1). 